\title{
Opto-electromagnetics-dielectric impulses in gel grown manganese mixed cadmium oxalate crystalline materials
}

\author{
Nagaraja K. P. ${ }^{1, *}$, Delma D’Souza ${ }^{l}$, and Ganavi A. S. ${ }^{l}$ \\ ${ }^{I}$ Department of Physics, FMKMC College (A constituent college of Mangalore University), Madikeri- \\ 571201
}

Email: nagarajkodip@gmail.com

\begin{abstract}
Manganese mixed cadmium oxalate (MMCO) crystalline materials were grown from optimized oxalic acid reinforced silica hydro gel using single test tube gel diffusion technique. Novel MMCO crystals were hard, transparent, water insoluble and exhibited high corrosion resistance. Fore grounded crystals were characterized using spectroscopic and analytical techniques. MMCO crystals inborn with cationic distribution $\mathrm{Cd}^{2+}: \mathrm{Mn}^{2+}$ of $1.356: 1$ and functional units: $\mathrm{O}-\mathrm{H}, \mathrm{C}=\mathrm{O}, \mathrm{C}-\mathrm{O}, \mathrm{C}-\mathrm{C}$ and $\mathrm{Cd}: \mathrm{Mn}-\mathrm{O}$ in the crystal armature. MMCO crystal constituted with a chemical formula $\mathrm{Cd}_{0.576} \mathrm{Mn}_{0.424}\left(\mathrm{C}_{2} \mathrm{O}_{4}\right) \cdot 3 \mathrm{H}_{2} \mathrm{O}$, molecular weight of 230.108 and crystallizes in triclinic geometry. Optical studies reveal absorption in UV region and maximum transmittance in visible region. Electromagnetic and dielectric studies spotlighted the existence of displacement current density, dielectric constant of 59.94 and capacitance of $47.90 \mathrm{pF}$. The new crystalline material ingrains an electrical resistivity of $0.342 \times 10^{7} \Omega \mathrm{m}$ and allows very feeble current (few $\mathrm{nA}$ ) to flow through them. Indeed, due to spectrum of intrinsic characteristics, MMCO crystal materials find wide applications in material science and microelectronics.
\end{abstract}

Keywords: absorption, crystal, dielectric, displacement, silica

\section{Introduction}

An account of simplicity, inexpensive growth equipments and adaptability, gel technique is widely used to grow good quality pure water insoluble crystals $[1,2]$. In a silica hydro gel growth media oxalate $\left(\mathrm{C}_{2} \mathrm{O}_{4}\right)^{2-}$ ion easily multiplexes with mono, di, tri and tetravalent metal cations and forms crystal globules which could generate spectrum of doped, co-doped and mixed crystals [3,4]. Engraved crystals when characterized few exhibited semiconducting properties, majority grew as insulators with subclass showed special dielectricity and some are piezo electric in nature [5,6]. Review of past investigations stimulated us to grow good quality oxalate crystals which would reach modern electronics needs. In view of these, as a part of research work carried out by us, the present article reports the growth of manganese mixed cadmium oxalate crystals, their characterization and opto-electromagnetic impulses. 


\section{Materials and methods}

\subsection{Growth of manganese mixed Cadmium oxalate crystals}

MMCO crystals were grown using gel technique in silica hydro gel growth media [7]. Optimized growth environment was established with the aid of gel temperature diagram. Gel media of SMS specific gravity $1.0375 \mathrm{~g} / \mathrm{cm}^{3}$, gel $\mathrm{pH} 4.25$ with supernatant solution mixture containing $\mathrm{CdCl}_{2}(0.5 \mathrm{M})$ and $\mathrm{MnCl}_{2}(0.5 \mathrm{M})$ in the doping ratio of 4:2 was suitable for the growth of MMCO crystals. The chemical process which describes the growth of MMCO crystal is as follows.

$$
\mathrm{Mn}^{2+}+\left(\mathrm{CdCl}_{2}\right) 2.5 \mathrm{H}_{2} \mathrm{O}+\left(\mathrm{C}_{2} \mathrm{H}_{2} \mathrm{O}_{4}\right) 2 \mathrm{H}_{2} \mathrm{O} \rightarrow \mathrm{Mn}: \mathrm{Cd}\left(\mathrm{C}_{2} \mathrm{O}_{4}\right) \cdot 3 \mathrm{H}_{2} \mathrm{O}+2 \mathrm{HCl}+1.5 \mathrm{H}_{2} \mathrm{O}
$$

Optimum condition for growth of the mixed crystal is recorded in Table 1. Fig. 1 illustrates the growth and extraction of MMCO crystals.

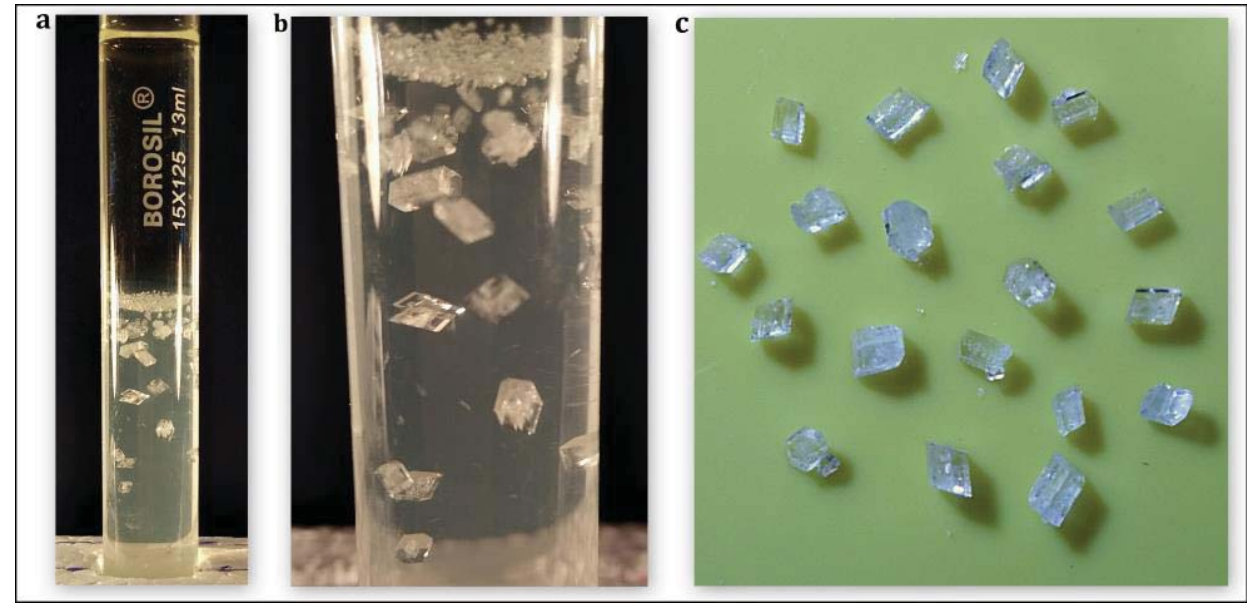

FIG 1. (a, b) Growth and (c) extracted MMCO crystals.

Table 1. Optimum growth aspects of MMCO crystals.

\begin{tabular}{|l|l|}
\hline Parameter & Optimum condition \\
\hline Specific gravity of SMS & $1.0375 \mathrm{~g} / \mathrm{cm}^{3}$ \\
\hline Gel pH & 04.25 \\
\hline SMS: Oxalic acid & $5: 4$ \\
\hline Mixture ratio & $4: 2$ \\
\hline Growth period & 20 days \\
\hline Chemical formula & Mn: $\mathrm{Cd}\left(\mathrm{C}_{2} \mathrm{O}_{4}\right) \cdot 3 \mathrm{H}_{2} \mathrm{O}$ \\
\hline Colour & Cloudy white \\
\hline Physical appearance & Hard, transparent \\
\hline
\end{tabular}

2.2. Characterization

38 INTERNATIONAL JOURNAL OF INNOVATIVE RESEARCH IN PHYSICS 
Elemental analysis of the crystal was done using energy dispersive X-ray spectrum (EDX) using CARL ZIESS FESEM attached with EDS. Thermal stability and decomposition behavior of the MMCO crystals were measured using Perkin Elmer Pyris TGA instrument. FTIR spectrum of the mixed crystal was recorded per wavelength range of 450 to $4000 \mathrm{~cm}^{-1}$ using IR Prestige-21 SHIMADZU calibrated in attenuated total reflectance. Structural characterization of mixed oxalate crystals were done using powder X-ray diffractometer Minflex 600 Rigaku having X-ray $\mathrm{Cu}-\mathrm{K}$ alpha radiation of wavelength $1.54 \AA$ with a scan speed of $1 \%$ minute. Energy gap associated with the MMCO crystals was determined using UV-Vis spectrophotometer (UV-1800 SHIMADZU) for the spectral range of 200-1200nm followed by tauc plot. Further, electrical conductivity measurements and V-I characteristics of the mixed crystals were carried out in the range $0-1000 \mathrm{mMho} / \mathrm{cm}$ using Mittal instruments and Keithley source measuring instrument 2450 respectively. Dielectric studies of mixed crystals were carried out using Mittal instruments 2151/T-7C calibrated to generate sine wave for frequency $253.88 \mathrm{kHz}$ in DSO.

\section{Results and discussion}

Quantitative and elemental analysis of MMCO crystals was done using EDAX measurements. Fig. 2 shows the EDAX spectrum of the crystal. Spectrum exhibits prominent peaks due to $\mathrm{Cd}, \mathrm{Mn}, \mathrm{O}$ and $\mathrm{C}$ associated with the crystal. The weight [\%] and atomic [\%] of constituent elements of the crystal were recorded in Table 2. Fig. 3 illuminates the SEM image of MMCO crystal.

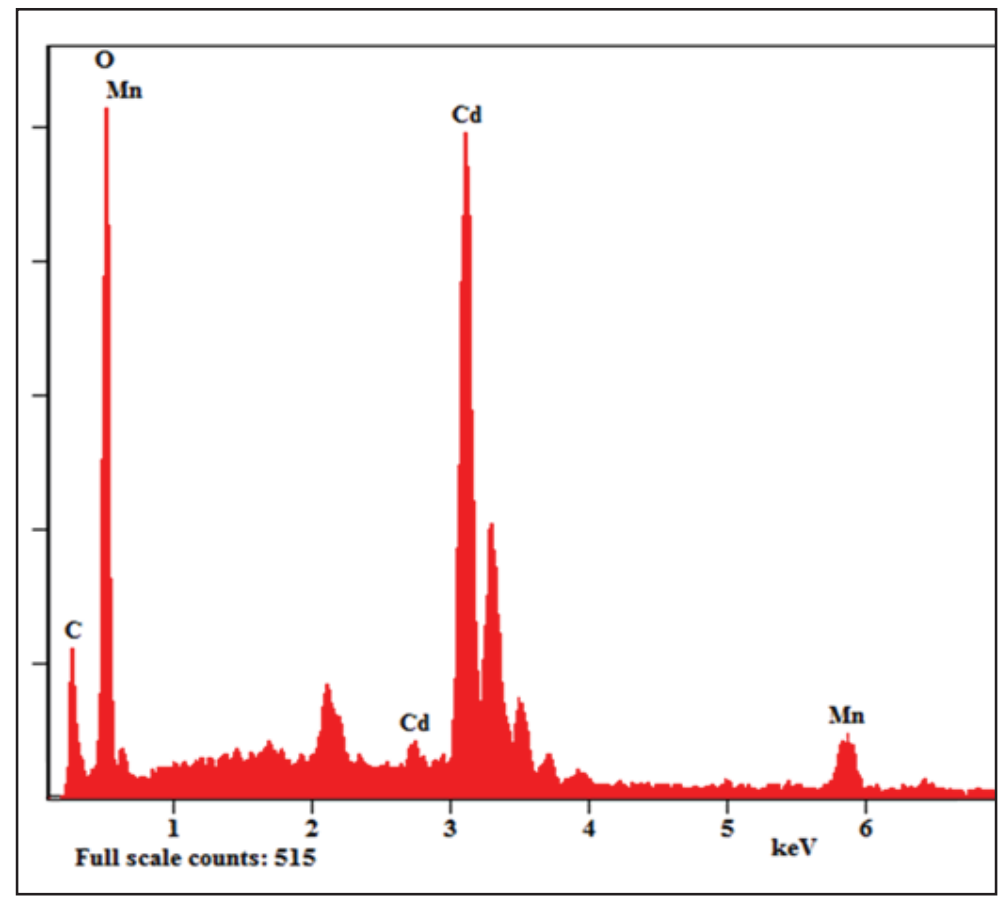

FIG 2. EDAX spectrum of MMCO crystal. 


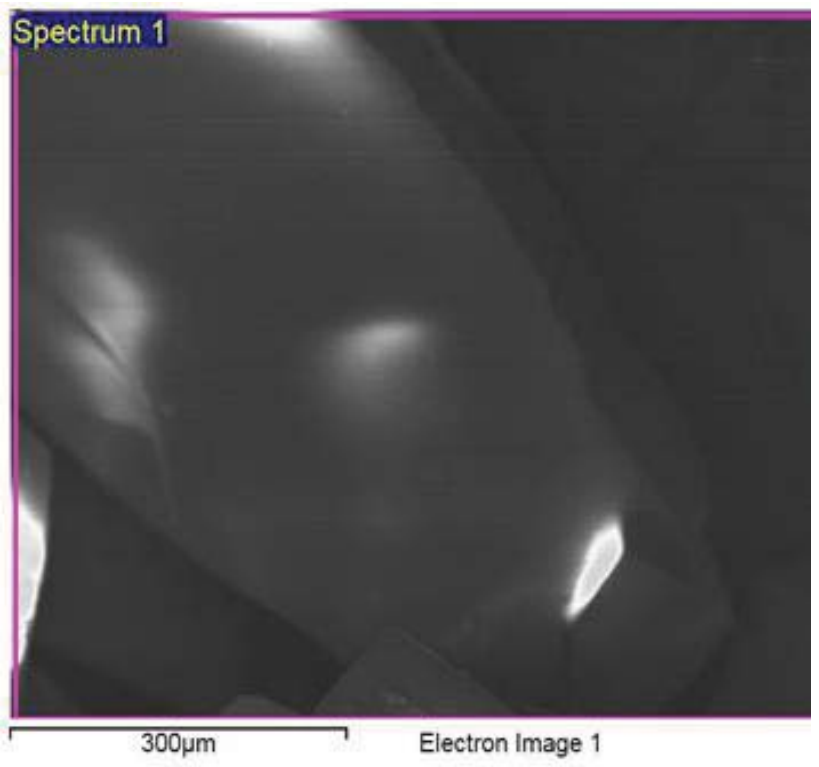

FIG 3. SEM image of MMCO crystal.

Table 2. EDAX results of MMCO crystal.

\begin{tabular}{|l|l|l|l|l|}
\hline Crystal & $\begin{array}{l}\text { Elements } \\
\text { present }\end{array}$ & Weight \% & Atomic \% & $\begin{array}{l}\text { Cationic } \\
\text { distribution }\end{array}$ \\
\hline \multirow{4}{*}{ MMCO } & $\mathrm{Cd}$ & 28.5 & 5.45 & \\
\cline { 2 - 4 } & $\mathrm{Mn}$ & 10.25 & 4.02 & \\
\cline { 2 - 4 } $\mathrm{Cd}^{2+}: \mathrm{Mn}^{2+}$ & & \\
& $\mathrm{O}$ & 44.50 & 60.37 & \\
\cline { 2 - 4 } & $\mathrm{C}$ & 16.75 & 30.16 & \\
\cline { 2 - 4 } & Total & 100 & 100 & \\
\hline
\end{tabular}

The TG plot (Fig. 4) of MMCO crystal consists of TG, DTG and DTA curves. The thermogravimetric analysis of MMCO crystals revealed that, there are two decomposition stages in the temperature range 59 to $396^{\circ} \mathrm{C}$. In the first decomposition stage, MMCO crystal lost three water molecules in the $\mathrm{T}_{\mathrm{d}}$ range of 59 to $147^{\circ} \mathrm{C}$ with a weight loss of $22.5 \%$ (calculated loss: $23.48 \%$ ), which corresponds to $\mathrm{T}_{\text {DTG }}$ peak at $118^{\circ} \mathrm{C}$ and endothermic $\mathrm{T}_{\text {DTA }}$ peak at $125.5^{\circ} \mathrm{C}$ respectively. The dehydrated MMCO crystal further decomposed in $\mathrm{T}_{\mathrm{d}}$ range between $282-396^{\circ} \mathrm{C}\left(\mathrm{T}_{\text {DTG }}\right.$ peak at $348^{\circ} \mathrm{C}$ and exothermic $\mathrm{T}_{\text {DTA }}$ peak at $\left.353.5^{\circ} \mathrm{C}\right)$ showing a weight loss of $29.70 \%$ (calculated loss:31.29\%) due to the loss of $\mathrm{CO}$ and $\mathrm{CO}_{2}$ molecules simultaneously. Eventually, MMCO crystals exhibited thermal stability upto $600^{\circ} \mathrm{C}$ in $\mathrm{Cd}: \mathrm{Mn}-\mathrm{O}$ state. Table 3 and Table 4 give the thermogravimetric parameters of MMCO crystals. The chemical formula of MMCO crystal is $\mathrm{Cd}_{0.576} \mathrm{Mn}_{0.424}\left(\mathrm{C}_{2} \mathrm{O}_{4}\right) .3 \mathrm{H}_{2} \mathrm{O}$ with a molecular weight of 230.1079 . 


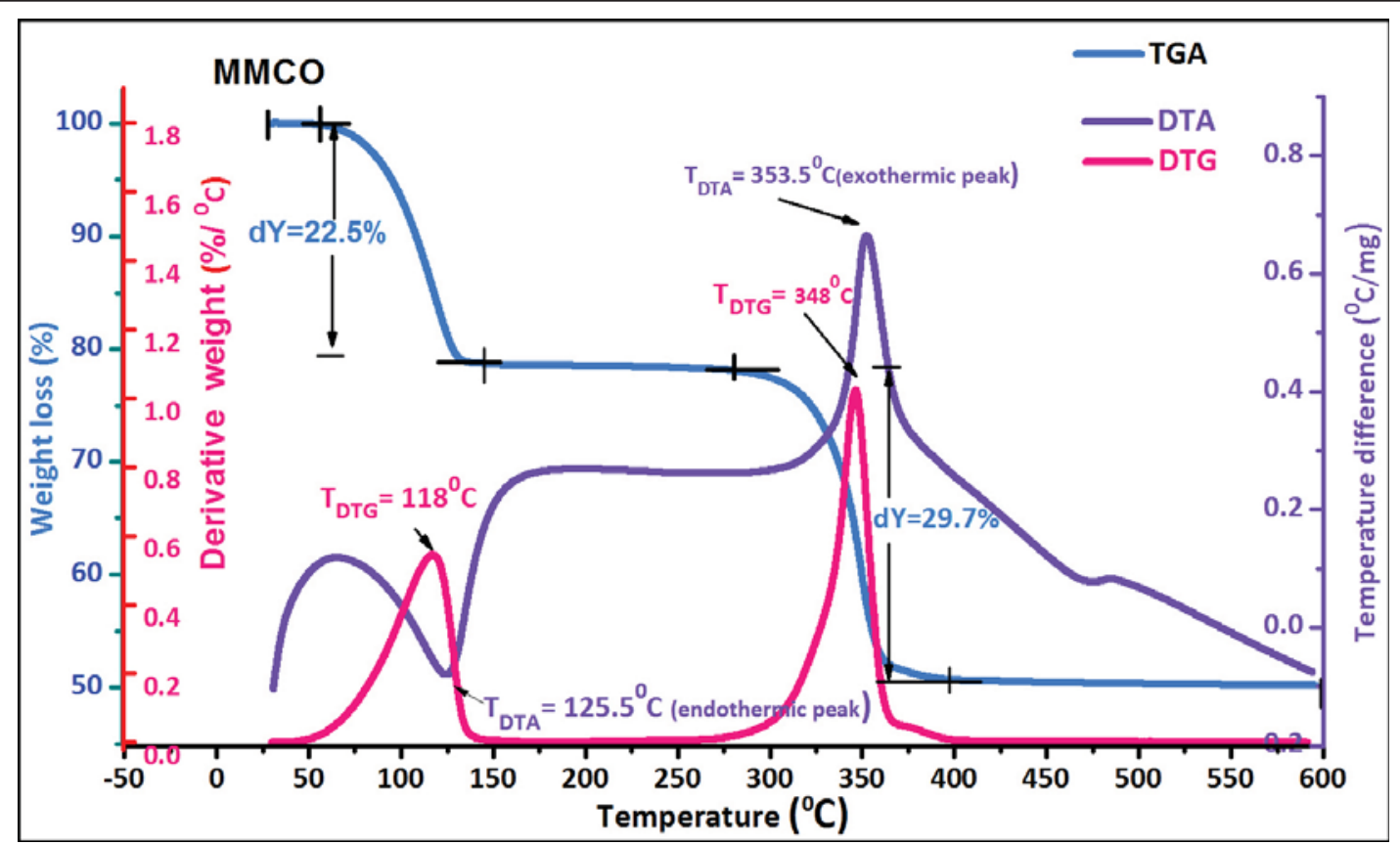

FIG 4. TG plot of MMCO crystals.

Table 3. TG results of MMCO crystals.

\begin{tabular}{|c|c|c|c|c|c|c|}
\hline \multirow[t]{2}{*}{ Phase } & \multirow{2}{*}{$\begin{array}{l}\mathrm{T}_{\mathrm{d}} \text { range } \\
{ }^{\circ} \mathrm{C}\end{array}$} & \multirow{2}{*}{$\begin{array}{l}\mathrm{T}_{\mathrm{DTG}} \\
{ }^{\circ} \mathrm{C}\end{array}$} & \multirow{2}{*}{$\begin{array}{l}\mathrm{T}_{\mathrm{DTA}} \\
{ }^{\circ} \mathrm{C}\end{array}$} & \multicolumn{2}{|c|}{ Weight loss (\%) } & \multirow{2}{*}{$\begin{array}{l}\text { Chemical formula/ } \\
\text { Molecular weight }\end{array}$} \\
\hline & & & & Observed & Calculated & \\
\hline I & $59-147$ & 118.0 & 125.5 & 22.5 & 23.48 & $\mathrm{Cd}_{0.576} \mathrm{Mn}_{0.424}\left(\mathrm{C}_{2} \mathrm{O}_{4}\right) \cdot 3 \mathrm{H}_{2} \mathrm{O}$ \\
\hline II & $282-396$ & 348.0 & 353.5 & 29.7 & 31.29 & 230.108 \\
\hline
\end{tabular}

Table 4. Decomposition behavior of MMCO crystals.

\begin{tabular}{|l|l|l|}
\hline Phase & Decomposition process & Decomposed molecule \\
\hline I & $\mathrm{Cd}_{0.576} \mathrm{Mn}_{0.424}\left(\mathrm{C}_{2} \mathrm{O}_{4}\right) .3 \mathrm{H}_{2} \mathrm{O} \rightarrow \mathrm{Cd}_{0.576} \mathrm{Mn}_{0.424}\left(\mathrm{C}_{2} \mathrm{O}_{4}\right)+3 \mathrm{H}_{2} \mathrm{O}$ & $3 \mathrm{H}_{2} \mathrm{O}$ \\
\hline II & $\mathrm{Cd}_{0.576} \mathrm{Mn}_{0.424}\left(\mathrm{C}_{2} \mathrm{O}_{4}\right) \rightarrow \mathrm{Cd}_{0.576} \mathrm{Mn}_{0.424} \mathrm{O}+\mathrm{CO}+\mathrm{CO}_{2}$ & $\mathrm{CO}+\mathrm{CO}_{2}$ \\
\hline
\end{tabular}

FTIR spectrum of MMCO crystal is shown in Fig. 5 with the wavenumber range of $400-4500 \mathrm{~cm}^{-1}$ and the band assignments are listed in the Table 5. The fingerprint region of the spectrum confirms the presence of $\mathrm{Cd}-\mathrm{O}$ and $\mathrm{Mn}-\mathrm{O}$ bonds in the crystal lattice. In the FTIR spectrum of MMCO crystals, the broad band ranging from 3700 to $2974 \mathrm{~cm}^{-1}$, reveals the symmetric and asymmetric stretching of $\mathrm{O}-\mathrm{H}$ group which confirms the presence water molecules. Strong asymmetrical band at $1593 \mathrm{~cm}^{-1}$ is attributed as $\mathrm{C}=\mathrm{O}$ stretching of carboxylate ion. The sharp absorption peak at $1313 \mathrm{~cm}^{-1}$ is due to $\mathrm{C}-\mathrm{C}$ vibrations and C-O stretching. Intense absorption peaks at $1056-1011 \mathrm{~cm}^{-1}$ related to $\mathrm{C}-\mathrm{O}$ vibrations and the absorption peaks at $598-419 \mathrm{~cm}^{-1}$ corresponds to $\mathrm{M}-\mathrm{O}(\mathrm{M}=\mathrm{Cd}$ and $\mathrm{Mn})$ stretching of MMCO crystals $[4,8]$. 
Table 5. FTIR results of MMCO crystals.

\begin{tabular}{|l|l|l|}
\hline Sl. No. & Band assignments & Wave number $\mathrm{cm}^{-1}$ \\
\hline 01 & $\begin{array}{l}\text { Symmetric and asymmetric stretching } \\
\text { of OH group and water of crystallization }\end{array}$ & $3700-2974$ \\
\hline 02 & C=O stretching, O-H bending & 1593 \\
\hline 03 & C-C vibrations, C-O stretching & 1313 \\
\hline 04 & C- O absorptions & $1056-1011$ \\
\hline 05 & O-H out of plane bending & 788,721 \\
\hline 06 & M-O stretching & $648,598,514$ \\
\hline
\end{tabular}

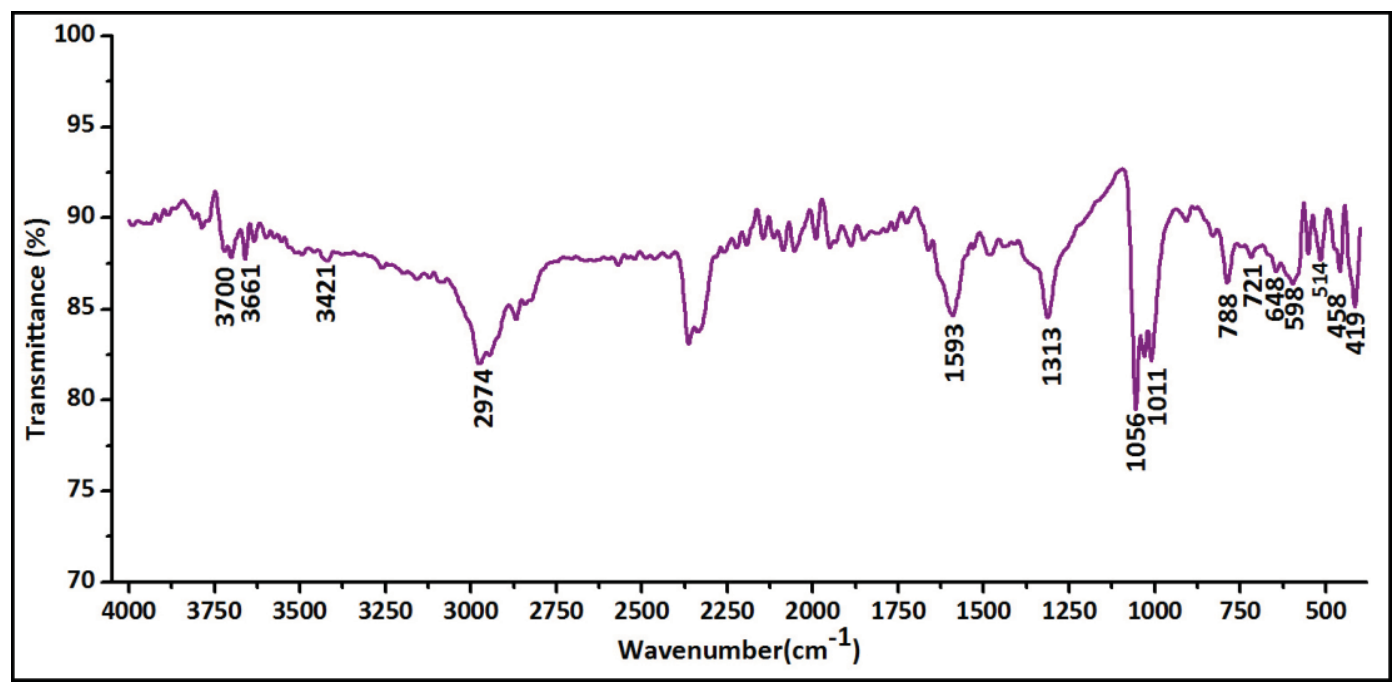

FIG 5. FTIR spectrum of MMCO crystal.

MMCO crystals (Powder form) subjected to PXRD analysis displayed well defined Bragg's diffraction peaks indicated high crystalline nature of the grown crystals (Fig. 6). Diffraction patterns were indexed using N-TREOR09 program. Resulted $d$-spacing and the Miller indices are in agreement with the standard values. Unit cell parameters of MMCO crystals were recorded in Table 6. MMCO crystallizes in triclinic geometry. 


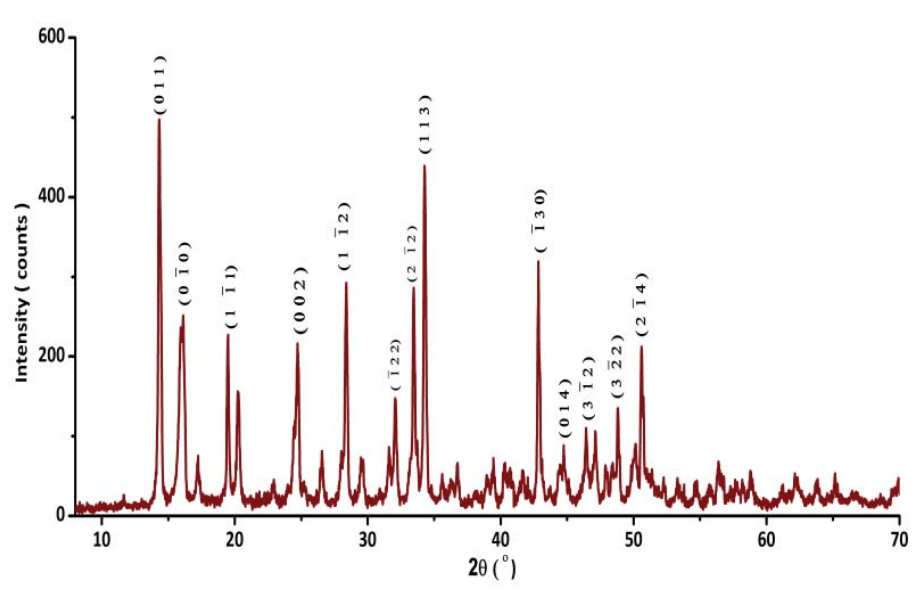

FIG 6. Powder XRD pattern of MMCO crystal.

Table 6. Cell parameters of MMCO crystal.

\begin{tabular}{|l|l|}
\hline Cell parameters & MMCO \\
\hline$a(\AA)$ & 5.998 \\
\hline$b(\AA)$ & 6.650 \\
\hline$c(\AA)$ & 8.460 \\
\hline$\alpha\left(^{\circ}\right)$ & 74.72 \\
\hline$\beta\left(^{\circ}\right)$ & 74.22 \\
\hline$Y\left(^{\circ}\right)$ & 115.01 \\
\hline Space group & $\mathrm{P} \overline{1}$ \\
\hline Crystal system & Triclinic \\
\hline
\end{tabular}

Optical properties of the mixed oxalate crystals were investigated using UV-visible spectroscopy. Fig. 7 elucidates UV-visible spectrum and tauc plot MMCO crystal. UV- visible spectral studies of MMCO crystal revealed that, crystal is highly transparent to visible light and showed absorption in the UV region. Mixed crystal possesses maximum absorption at $196 \mathrm{~nm}$ with $\mathrm{A}_{\max }=1.03$. MMCO crystal exhibits band gap energy of $6.021 \mathrm{eV}$ and behaves as insulator. 


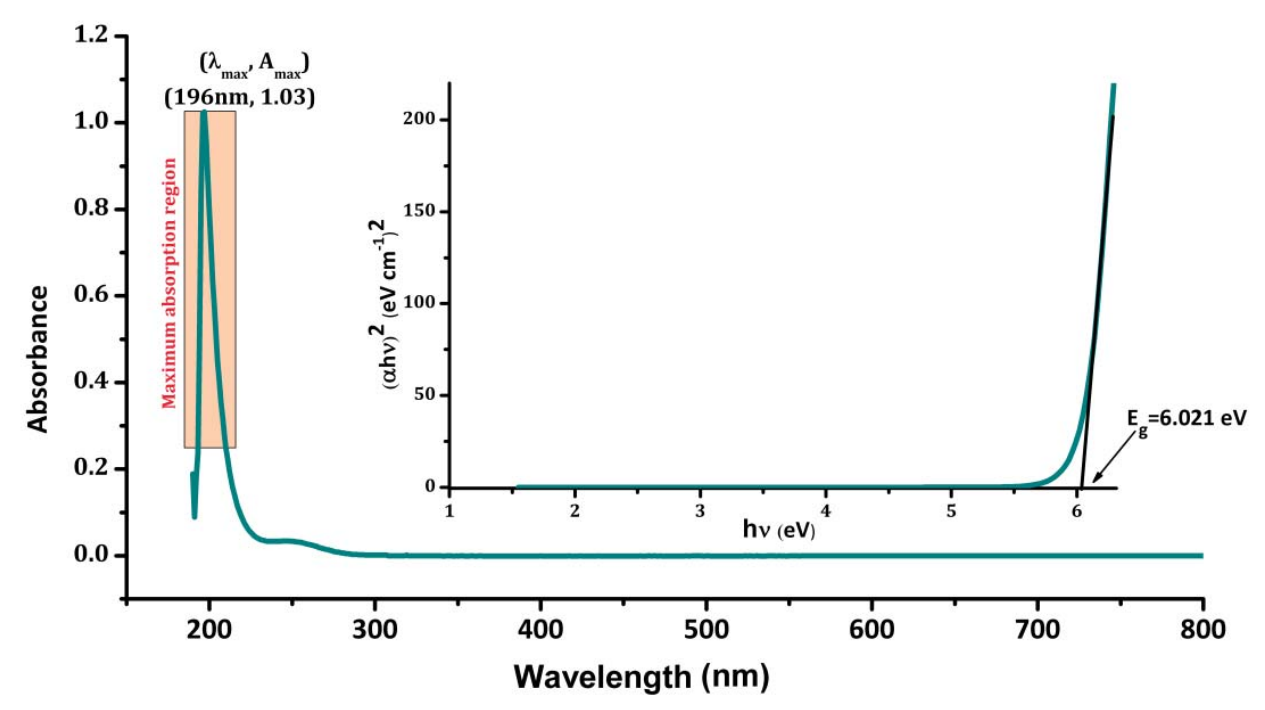

FIG 7. UV- visible spectrum and tauc plot of MMCO crystal.

Dielectric properties of MMCO crystal were measured by forming circular crystal pellets of thickness approximately $1 \mathrm{~mm}$ and area equals to the dimension of gold plated dielectric cell [9]. Measuring capacitance $(C)$ of the crystal pellet and approximating capacitance $\left(\mathrm{C}_{\mathrm{o}}\right)$ of air to the dimension of crystal pallet, the dielectric constant $\epsilon_{\mathrm{r}}$ of the crystal is measure as

$$
\epsilon_{\mathrm{r}}=\frac{C}{C_{o}}=\frac{47.90 \times 10^{-12}}{0.714 \times 10^{-12}}=59.94
$$

Complete electrical behavior of the MMCO crystal are elucidated by studying its volt- ampere (V-I) characteristics (Fig. 8). Using Keithley source measuring unit high dc voltage of $60 \mathrm{~V}$ is applied across the mixed crystal and measured the current. The crystal allowed very feeble current in nA; which grew linearly with applied voltage and recorded leakage resistance of $1.332 \mathrm{G} \Omega$. The opto-elecrical parameters are recorded in Table 7. 


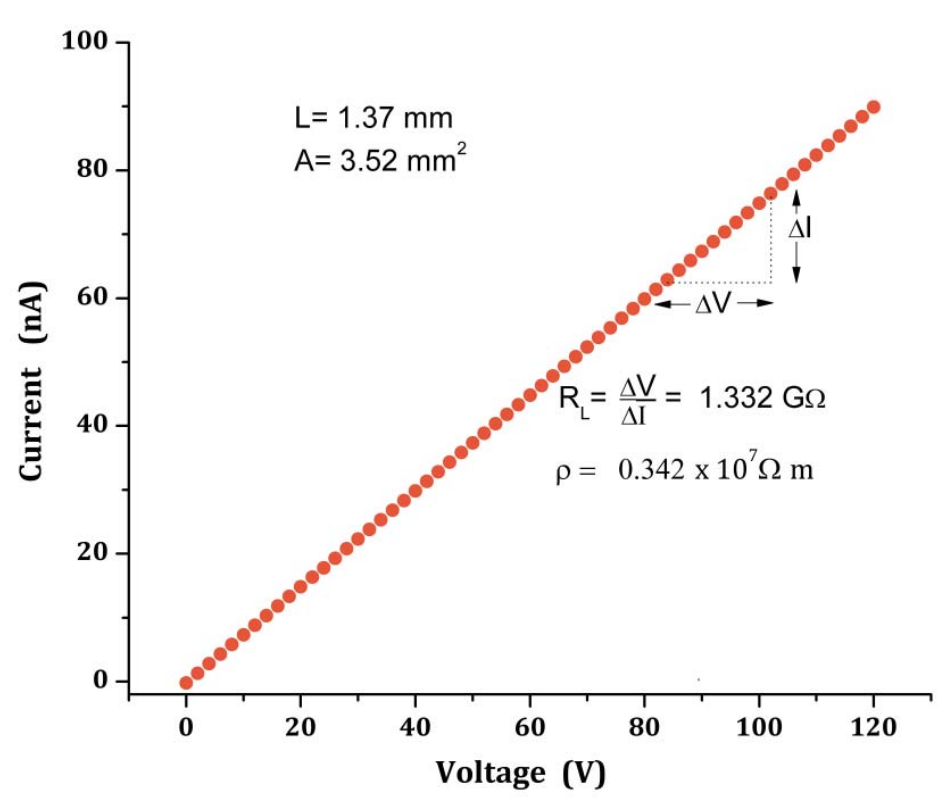

FIG 8. V-I characteristics of MMCO crystal.

Table 7. Opto-electrical parameters of MMCO crystal.

\begin{tabular}{|l|l|}
\hline Band gap energy $\mathrm{E}_{\mathrm{g}}(\mathrm{eV})$ & 6.021 \\
\hline Dielectric constant $\varepsilon_{\mathrm{r}}$ & 59.94 \\
\hline Capacitance $\mathrm{C}(\mathrm{pF})$ & 47.90 \\
\hline Leakage resistance $\mathrm{R}_{\mathrm{L}}(\mathrm{G} \Omega)$ & 1.332 \\
\hline Electrical resistivity $\rho(\Omega \mathrm{m})$ & $0.342 \times 10^{7}$ \\
\hline
\end{tabular}

One more interesting thing we notice that, MMCO exhibited special electro-magnetic behavior. When a steady current of $200 \mathrm{~mA}$ regulated to flow through MMCO crystal capacitor for applied DC voltage of $60 \mathrm{~V}$ using external circuit, it acted as open circuit and did not allowed any current to flow through it and behaved as perfect dielectric. However, when flow of current through the crystal varied instantly, permitted the DC current to flow through it; which satisfied Maxwell field equation $\vec{\nabla} \times \overrightarrow{\mathbf{H}}=\overrightarrow{\mathbf{J}}+\frac{\partial \overrightarrow{\mathbf{D}}}{\partial \boldsymbol{t}}[10]$.

It is clear that, in response to the time varying current $\mathrm{MMCO}$ crystal generated displacement current density $\frac{\partial \overrightarrow{\mathrm{D}}}{\partial t}$ within the dielectric and formed a closed circuit with conduction current flowing externally. Eventually 
due to this special electromagnetic attitude MMCO could be used as better dielectrics in microelectronic applications such as printed circuit boards, integrated circuits etc.

\section{Conclusion}

Gel temperature diagram aided, oxalic acid reinforced silica hydro gel yielded good quality MMCO crystals. The grown mixed crystal was characterized using spectroscopic and analytical techniques. The crystal artwork consists of $\mathrm{C}-\mathrm{C}, \mathrm{C}-\mathrm{O}, \mathrm{C}=\mathrm{O}, \mathrm{H}-\mathrm{O}-\mathrm{H}$ and $\mathrm{Cd}: \mathrm{Mn}-\mathrm{O}$ bonds. $\mathrm{MMCO}$ crystal ingrains a cationic distribution of 1.356: 1 (Cd:Mn) and bounds to a chemical formula $\mathrm{Cd}_{0.576} \mathrm{Mn}_{0.424}\left(\mathrm{C}_{2} \mathrm{O}_{4}\right) \cdot 3 \mathrm{H}_{2} \mathrm{O}$ (molecular weight 230.1079) with triclinic geometry. The crystal degraded in two stages (temperature limit $59-396^{\circ} \mathrm{C}$ ) and attained thermal stability in $\mathrm{Cd}: \mathrm{Mn}-\mathrm{O}$ (metal oxide) state above $600^{\circ} \mathrm{C}$. The opto-electric studies of MMCO crystal instigated band gap energy of $6.021 \mathrm{eV}$, linear variation of current (nA) with applied DC voltage encompassing leakage resistance of $1.332 \mathrm{G} \Omega$. The novel crystal embeds a dielectric constant of 59.94 (at calibrated sine wave frequency $253.88 \mathrm{kHz}$ ) unveiled a capacitance of $47.90 \mathrm{pF}$ for the dimension of gold plated dielectric cell. Indecently, MMCO exhibited special electro-magnetic behavior by generating displacement current density for the applied DC time varying current. Overall, the in-depth characterization of MMCO crystal signals special applications in microelectronics and high temperature electronics.

\section{Acknowledgements}

The authors are grateful to Principal, HOD of Physics, FMKMC college Madikeri, Chairman, Department of studies in Physics, University of Mysore, Mysuru, Coordinator, IOE, University of Mysore, Mysuru, Director, University science instrumentation center, Mangalore University and Scientific officer, DSTPURSE laboratory, Mangalore University, Mangalore for providing laboratory facilities.

\section{REFERENCES}

[1] Popalghat S K and Bhagat A C, International Journal of Recent Scientific Research 6, 2587 (2015)

[2] Ahmad N, Ahmad M M and Kotru P N, Journal of Crystal Growth 412, 72 (2015)

[3] Chelet-Araba B, Nowogrockia G, Abrahama F and Grandjean S, Journal of Solid State Chemistry 177,4269 (2017)

[4] Daisy Selasteen F, Alfred Cecil Raj S, Alagappa Moses A, Emalda Prince F, Esther Getsy R and Elakkiya R, Journal of Crystallization Process and Technology 6, 11 (2016)

[5] Minu Mary C, Vimal G, Kamal Mani P, Gijo Jose, Biju P R, Joseph C, Unnikrishnan N V and Ittyachen M A Journal of Materials Research and Technology 5, 268 (2016)

[6] Prasad N V, Prasad G, Bhimasankaram T, Suryanarayana S V and Kumar G S, Bulletin of Materials Science 19, 639 (1996)

[7] Patel A R and Venkateswara Rao A, Bulletin of Materials Science 4, 527 (1982) 
[8] Chandran S, Paulraj R and Ramasamy P, Optical Materials 73, 154 (2017)

[9] Rasal Y B, Anis M, Shirsat M D, and Hussaini S S Materials Research Innovations 21, 45 (2016)

[10] Mechael A S J, Measurement of depletion voltage and leakage current, Manchester University, Manchester (2002) 